\title{
Por fuera de los sindicatos: experiencias clasistas en fábricas pequeñas y medianas de Córdoba, 1969-1971
}

\author{
[Outside of the Unions: Clasistas Experiences \\ in small and medium Factories of Córdoba, 1969-1971] \\ María Laura Ortiz \\ Universidad Nacional de Córdoba- \\ Centro de Estudios Avanzados, CONICET \\ malauraortiz@gmail.com
}

\begin{abstract}
Resumen
En este artículo se analizan experiencias clasistas desarrolladas en establecimientos pequeños y medianos de Córdoba entre 1969 y 1971. En distintas fábricas metalúrgicas, de calzado, de vidrio y obras de construcción; surgieron agrupaciones clasistas a partir de una situación de descontento obrero que no tuvo canalización a través de la estructura sindical existente. Por lo tanto, su organización buscó espacios al margen de los sindicatos, aunque no pudo institucionalizarse para disputar la dirección sindical. Para ello fue sustancial la operatividad de la violencia empresaria, del gobierno y de las cúpulas sindicales.
\end{abstract}

Palabras clave: Clasismo - Sindicatos - Represión.

\begin{abstract}
This article discusses clasistas experiences developed in small and medium factories of Córdoba between 1969 and 1971. In different metallurgical factories, footwear, glass and construction site; clasistas association emerged from a situation of worker discontent that had no channeling through the existing union structure. Therefore, his organization looked for spaces outside the unions, although it could not be institutionalized to dispute the union leadership. To this end the operation of corporate violence, the government and trade union leadership was substantial.

Keywords: Clasismo - Trade Union - Repression.
\end{abstract}

Recibido: 31/01/2018

Evaluación: 23/08/2018

Aceptado: 06/11/2018

Anuario de la Escuela de Historia Virtual - Año 9 - N 14 - 2018: pp. 81-99.

ISSN: 1853-7049

http://revistas.unc.edu.ar/index.php/anuariohistoria 


\section{Por fuera de los sindicatos: experiencias clasistas en fábricas pequeñas y medianas de Córdoba, 1969-1971}

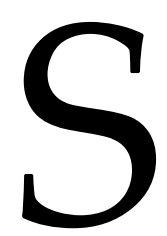

i bien el sindicalismo clasista se manifestó en distintas provincias argentinas y en otros puntos del mundo, tuvo un desarrollo temprano y aparentemente espontáneo en Córdoba, en el marco de una profunda movilización política luego del "Cordobazo" (1969). Mucho se ha escrito y discutido acerca de ese hecho histórico: para algunos, el "Cordobazo" fue el punto final de una serie de luchas sociales que se manifestaban desde 1956 (Garzón Maceda, 1994, p. 26), pero, para otros autores, fue el "mito" fundante de las luchas políticas que atravesaron a todo el país hasta marzo de 1976 (Altamirano, 1994, p. 12; Brennan y Gordillo, 1994, pp. 7374; Ollier, 1986, pp. 31-33). Lo cierto es que, luego de esa insurrección popular, Córdoba no volvió a ser la misma, como así tampoco las representaciones que de esta ciudad tuvo el resto del país. En palabras de Mónica Gordillo, a partir de ese momento se expandió el ciclo de protesta social, que pasó de la resistencia a la confrontación (Gordillo, 2001, p. 33). Tortti agrega que con el "Cordobazo" se inició un período de movilización social ofensiva contra la dictadura, sobre todo, considerando que las reivindicaciones se expresaban en consignas que excedían lo sectorial. Ese tipo de protesta insurreccional evolucionó rápidamente hacia una acción política de carácter masiva al articularse con la oposición que despertaba la dictadura militar de la autoproclamada "Revolución Argentina" (Tortti, 1998, pp. 21-22). Parafraseando a María Matilde Ollier, podemos decir que durante este período se forjó una cultura política revolucionaria, es decir, un conjunto de mitos, creencias, creaciones, prácticas, valores, ideología que alimentaron el devenir político de la sociedad a partir de la acción (Ollier, 1986, p. 111, 128). Esa cultura política posibilitó además la emergencia del clasismo, aunque ciertamente no es condición suficiente para su explicación.

La cuestión del clasismo y el sindicalismo combativo ha sido estudiada ampliamente en Argentina, tanto en el ámbito académico, como en el político y en el diverso espacio de las memorias de militancia. Si bien los análisis han sido variados, de acuerdo a diferentes objetivos y teorías contrapuestas, la mayoría de los estudios sobre el sindicalismo clasista lo han definido por la virulencia de sus medidas de fuerza, destacando, sobre todo, las "huelgas salvajes" que buscaban romper la legalidad burguesa. Asimismo, la incidencia de distintas organizaciones de la izquierda revolucionaria en su conformación se hizo evidente en sus lemas antiburocráticos, antipatronales y anticapitalistas, en pro de una democratización sindical que ampliase la participación activa de las bases obreras (Ortiz, 2010). La mayor parte de estas producciones se refieren al estudio de unos pocos casos, seleccionados por la importancia de sus acciones, por la representatividad de sus 
83 | Por fuera de los sindicatos: experiencias clasistas...

dirigentes o por la disponibilidad de fuentes históricas. En lo referido a Córdoba, el clasismo pareciera circunscribirse al Sindicato de Trabajadores de FIAT Concord y Materfer (SiTraC y SiTraM) entre 1970 y 1971 y, en segundo término, al del Sindicato de Mecánicos y Afines del Transporte Automotor (SMATA) entre 1972 y 1974. Estos fueron casos que repercutieron en diversos puntos del país y, evidentemente, su trascendencia fue posible gracias al éxito en la estrategia de los clasistas para alcanzar la dirección sindical. Sin embargo, el clasismo fue un fenómeno más amplio y se nutrió de distintas experiencias que surgieron en otros sectores de la industria y los servicios, tales como fábricas mecánicas y metalúrgicas, de vidrio, de calzado, de caucho, en establecimientos lácteos, de la carne, en obras de construcción y en sectores de servicios como el de la sanidad y los empleados públicos. En estos otros espacios, los clasistas no llegaron más allá de la conformación de una agrupación sindical, o de constituir mayorías en cuerpos de delegados $\mathrm{y}$, o comisiones internas de reclamos, o bien del intento de formar sindicatos paralelos. Allí, el acceso a la comisión directiva del sindicato fue un camino vedado por diferentes obstáculos, que dependieron de las prácticas y estatutos de cada sindicato, pero también estuvieron condicionados por los diferentes contextos sociopolíticos.

Partiendo de esta mirada, el objetivo de este artículo es reconstruir algunas de esas otras experiencias clasistas que se desarrollaron durante los años 1969 a 1971 en Córdoba, específicamente en fábricas metalúrgicas, de producción de calzado, de vidrio y en obras de construcción. En todos estos casos, el proceso de conformación de agrupaciones clasistas debió enfrentar la represión de las cúpulas sindicales, de las fuerzas de seguridad y de las patronales empresarias, que representaron la frontera de los horizontes de posibilidad, no para su emergencia, pero sí para su consolidación dentro de la institución sindical.

Lamentablemente, la conservación de fuentes documentales propias de estas agrupaciones ha sido escasa, casi nula. Por ello, este trabajo inició con un relevamiento minucioso de diarios de distribución masiva, especialmente, La Voz del Interior y Córdoba, en cuyas columnas sindicales aparecían algunos datos extraídos de comunicados de prensa o noticias sobre asambleas, acciones huelguísticas y otras declaraciones. Asimismo, se accedió a algunos testimonios de protagonistas, los que fueron trabajados a partir de las herramientas metodológicas de la historia oral. Con esos fragmentos se fueron reconstruyendo estas trayectorias a las que, seguramente, se podrán seguir agregando, corrigiendo y observando diversos aspectos. Este es solo el comienzo de un intento por reconocer sujetos sociales que actuaron en el pasado reciente, cuyas voces aún no han sido debidamente escuchadas.

Para muchos de los protagonistas de la época, la experiencia del activismo clasista se nutrió del ejemplo de los sindicatos de FIAT Concord y Materfer (SiTraC y SiTraM), según sus propias necesidades y sus posibilidades históricas. La excepcionalidad del clasismo en FIAT radicó en haber sido uno de los pocos casos en los que los clasistas lograron dirigir el sindicato e, incluso, en haber sido los primeros en hacerlo en aquel clima 
revolucionario posterior al "Cordobazo". Probablemente por estas características, el de SiTraC y SiTraM es uno de los casos más estudiados y con más textos publicados.

Desde que se constituyeron estos sindicatos, en 1965, los trabajadores de FIAT no protagonizaron conflictos importantes que movilizasen a las bases, al menos, hasta el "Cordobazo". Los sucesos de mayo de 1969 exacerbaron sus ánimos, aunque no de manera instantánea, ya que estos sindicatos no convocaron a sus trabajadores a participar de la movilización. Sin embargo, el hecho transformó gradualmente las percepciones sobre la capacidad de protesta de los trabajadores. ${ }^{1}$ Esto se expresó en un aumento notable de la actividad obrera, que mantuvo paralizaciones de tareas en las plantas y quites de colaboración en reclamo por mejoras salariales y en las condiciones de trabajo.2 Según los testimonios de algunos activistas, este redescubrimiento comenzó a agitar a las bases para rechazar una propuesta de convenio colectivo que había negociado la Comisión Directiva (CD) liderada por Lozano con la patronal de FIAT. ${ }^{3}$ Luego, los delegados aprobaron el convenio sin mandato de los operarios en una reunión de la que, al salir, tuvieron que pedir protección a la guardia interna de la fábrica ante la indignación de los obreros. La autoorganización de las bases decidió parar dos horas por turno en señal de repudio a la acción de la dirección sindical. Los diarios indicaron que las bases habían "retirado la confianza" en sus dirigentes por "total inoperancia y despreocupación manifiesta por los intereses de los trabajadores". ${ }^{4}$ Lo mismo recuerdan algunos de los protagonistas de ese proceso de democratización del SiTraC, que aseguran que lo que los guió en ese momento fue la espontaneidad, orientados por la sensación de injusticia y la pasividad de los dirigentes gremiales. ${ }^{5}$ Ante esa pasividad de la dirigencia, las bases obreras decidieron actuar: rechazaron el convenio y desconocieron a su dirección sindical, formando una Comisión Provisoria constituida por obreros elegidos entre sus compañeros (Duval, 2001; Flores, 2004). Pero esa Comisión demoraba en ser reconocida y, por ello, los obreros de Concord tomaron la fábrica con los jefes como rehenes y rodearon el establecimiento con tanques de líquido altamente inflamable y bombas molotovs. En esa ocasión, la acción obrera no fue reprimida e, incluso, fue imitada por sus compañeros de FIAT Materfer, quienes expulsaron a "la dirección amarilla" encabezada por Hugo Casanova (Flores, 2004, p. 152). ${ }^{6}$ En la misma época, se desarrollaron otras “huelgas sal-

\footnotetext{
${ }^{1}$ Entrevista a C. Masera, secretario general del SiTraC, realizada en Córdoba el 14/12/2010 por Laura Ortiz.

${ }^{2}$ FIAT había establecido tres plantas en Córdoba: Concord, que producía autos y camiones; Materfer que fabricaba equipos ferroviarios y Grandes Motores Diesel (GMD), que hacía lo propio con motores para camiones, ómnibus y locomotoras. Las dos primeras fábricas tenían sindicato por planta, mientras que GMD fue encuadrado en el SMATA. Hemeroteca del Poder Legislativo de la Provincia de Córdoba (HPLPC), La Voz del Interior (LVI), 22/08/1969, p. 20; HPLPC, LVI, 13/09/1969, p. 19.

${ }^{3}$ Entrevista a D. Bizzi, Secretario Adjunto del SiTraC, realizada en Córdoba el 21/12/2010 por Laura Ortiz; Entrevista a C. Masera, cit.

${ }^{4}$ HPLPC, LVI, 05/04/1970, p. 32.

${ }^{5}$ Entrevista a D. Bizzi, cit.; Archivo de Historia Oral del Archivo y Comisión Provincial de la Memoria de Córdoba, Entrevista a S. Torres, Secretario de Organización del SiTraC, realizada en Córdoba el 23/10/2009. ${ }^{6}$ HPLPC, LVI, 28/04/1970, p. 18; HPLPC, LVI, 29/04/1970, p. 19; HPLPC, LVI, 15/05/1970, p. 19; HPLPC, LVI, 17/05/1970, p. 34; HPLPC, LVI, 06/06/1970, p. 11.
} 
85 I Por fuera de los sindicatos: experiencias clasistas...

vajes" en fábricas encuadradas en el SMATA, a partir de la organización de núcleos opositores a la dirección del sindicato encabezado por Elpidio Torres, pero estos últimos sí fueron reprimidos con despidos masivos (Gordillo, 1996). ${ }^{7}$

Generalmente se atribuye a los sindicatos de FIAT ser los representantes del clasismo, caracterizado por la autoorganización obrera, la intransigencia en sus peticiones y la violencia en sus repertorios de confrontación (Werner y Aguirre, 2009; Mignon, 2014). Sin embargo, como veremos en este trabajo, estas características fueron compartidas por obreros clasistas en otros sectores productivos, tanto de aquellos vinculados a las industrias dinámicas, como a los sectores vegetativos de la producción local. En estas experiencias, el enfrentamiento de los trabajadores con las patronales por reclamos salariales y laborales se generó desde las bases obreras por fuera de las estructuras sindicales, cuyas dirigencias tradicionales, a su vez, mediaban en los conflictos para evitar que esas movilizaciones los desbordasen, como ocurrió en FIAT. En todos los casos que analizamos, lo lograron gracias a su capacidad negociadora, o merced al uso de la violencia. Agreguemos a estos elementos la existencia de un gobierno dictatorial con altas dosis represivas, todo lo cual dibuja un horizonte de posibilidades bastante reducido para las expresiones institucionales del clasismo. Sin embargo, que no hayan llegado a dirigir sus sindicatos no implica desconocer sus intentos de organización.

\section{El clasismo frente a la ortodoxia metalúrgica}

Durante el período analizado, la dirección sindical de la Unión Obrera Metalúrgica (UOM) se identificó con un posicionamiento "ortodoxo" dentro del peronismo. ${ }^{8}$ Para sostener su hegemonía en el sindicato, el núcleo dirigente recurría a diferentes estrategias: por un lado, controlaba la afiliación y participación electoral para evitar la inclusión de opositores que pudiesen generar una alternativa sindical y política; por otro, utilizaban la amenaza y la violencia física contra ellos. Pero, además, a lo largo de todo el período, la dirigencia de la UOM mantuvo su poder porque fue efectiva en la administración de los descontentos de las bases obreras (C. Wright Mills, citado en James, 2005, pp. 334-337), ya que mantuvo un alto grado de respuesta a las demandas de los trabajadores, aunque siempre resolviendo cada conflicto en el espacio mínimo necesario y evitando la conformación de redes horizontales entre trabajadores. Es decir, ante cada conflicto, la

\footnotetext{
${ }^{7}$ Hechos y Protagonistas de las luchas obreras argentinas. (1984), 1(1), p. 4.

${ }^{8}$ En este período, el Secretario General del gremio era Alejo Simó y el Adjunto Alfredo Martini. HPLPC, LVI, 05/06/1969, p. 20; HPLPC, LVI, 07/06/1969, p. 13. A fines de los años '60, los "ortodoxos" se definieron así para remarcar su adhesión intransigente a los principios peronistas y distinguirse del sector "legalista", más dispuesto a la negociación con el Estado y a competir por el liderazgo de Perón. Defendían el verticalismo como única forma de dar fidelidad incondicional a Juan Domingo Perón. Los “legalistas" se identificaban con una postura más progresista y, aunque también defendían la lealtad a Perón, cuestionaban la verticalidad a ultranza. Para ejercer una mayor representatividad sindical, los "legalistas" habían radicalizado su discurso a tono con las posturas de los "independientes" y "no alineados". Estos últimos aglutinaban a gremios no peronistas y reivindicaban un sindicalismo democrático, antiburocrático y con amplia participación de las bases (Brennan y Gordillo, 2008, pp. 34-47).
} 
dirigencia metalúrgica se investía de protagonista, poniéndose al frente de los reclamos obreros y encargándose de que la negociación resolviera -no siempre a mediano o largo plazo- las necesidades de los trabajadores metalúrgicos. Sin embargo, su estrategia combativa no implicó una postura contestataria ni mucho menos de izquierda, que sí estuvieron asociadas al clasismo.

En los días posteriores al "Cordobazo" la UOM se mantuvo en estado de alerta en repudio a la represión aplicada por el Estado. Como uno de los principales reclamos del paro que derivó en la insurrección del 29 de mayo de 1969 era la modificación de la Ley del Sábado Inglés, el sindicato metalúrgico advertía a sus afiliados que no debían aceptar ningún cambio de horario, puesto que el cambio de la ley aún no había sido reglamentado por el Poder Ejecutivo. Es decir, se mantiene una relativa actividad, sosteniendo un estado de alerta e informando a sus trabajadores, pero sin atacar el principal problema de los metalúrgicos, que también había sido uno de los desencadenantes del "Cordobazo": las quitas zonales. ${ }^{9}$ También se convocó a los afiliados a los paros y actos declarados por la CGT regional que, durante esta época, estaba hegemonizada por peronistas de la misma línea que la UOM. La verticalidad en su organización se desprende de sus discursos y acciones, por ejemplo, cuando en junio de 1969 emitían un comunicado convocando al acto de la CGT, pero advirtiendo que debían abstenerse de participar en cualquier otro acto, "a los efectos de no caer en la provocación y/o el juego interesado de sectores extremistas, de derecha o de izquierda interesados en desvirtuar la lucha del movimiento obrero y utilizarlo para sus fines particulares". ${ }^{10}$ Los argumentos de este comunicado sitúan al trabajador lejos de la agencia y remiten al discurso que interpretaba la "subversión" como única causa del problema de la violencia política, equiparando la violencia de derecha y de izquierda en un enfrentamiento del tipo de una "guerra", lo que derivó en la justificación de la Dictadura en 1976 (Franco, 2012, p. 64).

Decíamos que en las disputas con la patronal, la efectividad de la UOM fue relativamente alta y consistió en resolver cada conflicto particular, sin inducir a la creación de redes horizontales entre los trabajadores de los distintos establecimientos, que, en general, eran pequeños y medianos a diferencia de las fábricas encuadradas en el SMATA. ${ }^{11}$ Los sentidos que subyacían a esa combatividad se pusieron de manifiesto en el conflicto con la firma Aerometal Petrolini, a raíz de la deuda de dos quincenas de salario y la suspensión masiva de sus trabajadores. Los obreros decidieron abandonar sus tareas y

\footnotetext{
9 Para los metalúrgicos, el principal problema estaba en las quitas zonales más que en el "Sábado Inglés", ya que las patronales metalúrgicas fueron más reacias a cumplir con ellas. A fines de 1970 la Corte Suprema de Justicia dictó sentencia en un juicio sobre las quitas zonales considerándolas improcedentes, de manera que quedaba destruida la pretensión empresaria de quitar el 13\% del salario acordado en el convenio colectivo. HPLPC, LVI, 20/10/1970, p. 17.

${ }^{10}$ HPLPC, LVI, 15/06/1969, p. 34.

${ }^{11}$ Por ejemplo, en el conflicto con la Fábrica Metalúrgica Profile SRL, que estaba ubicada en calle Santa Ana 1766. Todo comenzó con el despido sin causa de un activista del gremio y tres operarios. Según el gremio se trataba de una maniobra para "quebrantar la unidad combativa del personal de la firma que lucha por sus reivindicaciones" y, por ello, se declaró un paro de 24 horas, aunque solo entre el personal del citado establecimiento. HPLPC, LVI, 28/06/1969, p. 18
} 
87 | Por fuera de los sindicatos: experiencias clasistas...

se reunieron frente al establecimiento, donde "improvisaron barricadas e interrumpieron el tráfico de la ruta № 9" ${ }^{12}$ En su gestión del conflicto, la UOM se puso a la cabeza de la actitud espontánea de los trabajadores, defendiendo la legitimidad de la medida. Al mismo tiempo, responsabilizó por todo a la empresa Renault -principal compradora de Aerometal- y solicitó la intervención de la Cámara de Industriales Metalúrgicos de Córdoba y del gobierno. Para ello, se entrevistó con el gobernador de facto Roberto Huerta, pidiéndole que gestionase créditos para Aerometal. ${ }^{13}$ Es decir, al mismo tiempo que el sindicato se ponía a la cabeza del movimiento de las bases en un rol de combatividad, no enfrentaba directamente a la patronal metalúrgica, sino que mantenía la cordialidad de las relaciones, apuntando, en cambio, a la patronal mecánica Renault.

Más allá de los frenos que imponía la $\mathrm{CD}$, lo cierto es que las bases metalúrgicas tenían un grado importante de actividad y, allí sí, la combatividad tenía un sentido crítico hacia las relaciones de poder. Por ello, un Congreso de Delegados votó en dos oportunidades a favor de declarar paro de todo el gremio en adhesión a los trabajadores de Aerometal Petrolini, por la exigencia del cumplimiento de la eliminación de las quitas zonales y por la libertad de todos los presos gremiales condenados, procesados o sin proceso. Durante la jornada del primer paro, en julio de 1969, la Policía informó que un patrullero fue apedreado por unos 40 trabajadores de Profile que no habían entrado a trabajar. ${ }^{14}$ Este tipo de actitudes eran aplaudidas por la Agrupación metalúrgica 1ํ de Mayo, que exhortaba a no declinar en la combatividad. Evidentemente, esta agrupación era opositora a la conducción, probablemente vinculada a la izquierda. Esto se colige de la actitud de la Comisión Directiva de la UOM, que conjuntamente con el Cuerpo de Delegados de Aerometal Petrolini S.A., emitieron un comunicado apuntando que la Agrupación 1o de Mayo no estaba constituida por trabajadores metalúrgicos y argumentaban: “Es innegable que se trata de un grupo perfectamente identificado, que no responde en absoluto a los intereses nacionales, y menos a los gremiales", que quieren crear dudas y "romper la unidad de la acción". Agregaban que el problema de Aerometal ya estaba solucionado e intimaban a los integrantes de esa agrupación a hacerse visibles para, probablemente, poder ser objeto de represalias. Decía la dirigencia de la UOM en una solicitada:

\footnotetext{
${ }^{12}$ HPLPC, LVI, 09/08/1969, p. 18.

${ }^{13}$ Aerometal Petrolini S.A. estaba ubicada sobre Ruta 9 a la altura del Km. 695 y en ella trabajaban 183 personas. Las gestiones del gobierno provincial consistieron en pedirle a Industrias Mecánicas del Estado (IME) que ayudara a Aerometal comprándole parte de su producción. Se firmó un compromiso para que IME comprase a Aerometal, por mes, 400 conjuntos de tapizados de asientos para Rastrojeros Diesel, suministrando IME a Aerometal la totalidad de los materiales para los mismos y facturando esa firma a IME únicamente la mano de obra. Aunque Aerometal no finalizó la entrega, IME adelantó igualmente el pago, para contribuir a solucionar el conflicto. Como veremos, no fue suficiente, y el conflicto continuó. HPLPC, LVI, 08/07/1969, p. 18; HPLPC, LVI, 10/08/1969, p. 31; HPLPC, LVI, 12/08/1969, p. 12; HPLPC, LVI, 15/09/1969, p. 13. En la segunda toma de Aerometal en abril de 1970, el abogado de la UOM, Sánchez Freites, negoció con un importante comerciante local (Jaime Lockman, uno de los principales acreedores de Aerometal) para que afrontase el pago de los jornales. HPLPC, LVI, 17/04/1970, p. 19. Tanto en un caso como en otro, las gestiones del gremio tendieron a la salida rápida del conflicto, sin hallar soluciones de fondo.

${ }^{14}$ HPLPC, LVI, 20/07/1969, p. 33; HPLPC, LVI, 27/07/1969, p. 31; HPLPC, LVI, 16/04/1970, p. 20.
} 
"Invitamos a los integrantes de esta agrupación fantasma autotitulada " 1 o de mayo" a concurrir a la asamblea general de trabajadores de Aerometal Petrolini (...) para que tengan la "valentía" de que hacen gala en la obscuridad, de sostener ante los propios trabajadores, sus acusaciones y argumentos y demostrar la veracidad de los mismos, así sabremos cómo y cuántos somos". ${ }^{15}$

Este fragmento presenta el tipo de organización de los clasistas con tintes de clandestinidad como táctica para evitar la represión con posibles despidos, traslados o agresiones físicas.

Junto a la Agrupación 1ํ de Mayo, existía la Agrupación Vanguardia Metalúrgica, de tendencia trotskista, que formaban parte de la oposición a la conducción del gremio. ${ }^{16}$ Sin embargo, esta oposición nunca logró institucionalizarse como tal, ya que el intento de formar una lista -la Verde- para participar de las elecciones sindicales de 1970 fue impugnada por la Junta Electoral metalúrgica. Por ello, tanto la Agrupación 1ํ de Mayo como la Lista Verde lanzaron duras críticas contra el proceso electoral metalúrgico, y la primera llamó a abstenerse de participar porque la consideraba una elección fraudulenta y proscriptiva, comandada por la "camarilla traidora de Simó". En respuesta, la Lista Blanca de la conducción apuntaba que los integrantes de la Verde no eran metalúrgicos. ${ }^{17}$ En el discurso de la dirección metalúrgica, el recurso al lenguaje amenazante se conjuga con la conformación de una identidad de los "otros" como lo externo al grupo de pertenencia: no son trabajadores, no son metalúrgicos y no son argentinos.

Las agrupaciones clasistas metalúrgicas apoyaban a las bases de Aerometal, pero el conflicto no se solucionaba y en los meses siguientes hubo nuevos atrasos en el pago de los jornales y los operarios decidieron ocupar la fábrica y tomar como rehenes al presidente y directivos de la firma. Alejo Simó medió entre el "afuera" y el "adentro" durante los dos días que duró la toma, hasta que llegó la orden judicial empuñada por el Jefe de la Policía local para desalojar la planta. Los obreros aceptaron levantar la toma, pero manteniendo las medidas de fuerza, ya que el conflicto no habría de terminar allí, sino que continuaría con nuevas faltas de pago, suspensiones, despidos y nuevas tomas, también, siempre con la misma modalidad. ${ }^{18}$

Por la misma época, los obreros de la fábrica metalúrgica Italbó la ocuparon en dos oportunidades, por faltas de pago y por el despido de 31 trabajadores. La empresa se excusaba en la baja de un $25 \%$ de las órdenes de entrega de su producción por parte de su principal compradora Renault. En la primera toma, en noviembre de 1969, circuló la versión de que habían incendiado la fábrica, pero el vocero de los trabajadores, Alejo Simó, salió a aclarar que el fuego era para hacer un asado, coligiendo que esta toma era

${ }^{15}$ HPLPC, LVI, 20/08/1969, p. 21.

${ }^{16}$ HPLPC, LVI, 07/02/1970, p. 13; HPLPC, LVI, 14/04/1970, p. 18; Entrevista a M.C. Carranza, delegada de la fábrica Cindalux (Vidrio) y militante del PST, realizada en Córdoba el 12/08/2011 por Laura Ortiz.

${ }^{17}$ HPLPC, LVI, 12/03/1970, p. 21; HPLPC, LVI, 13/03/1970, p. 18; HPLPC, LVI, 16/04/1970, p. 20.

${ }^{18}$ HPLPC, LVI, 10/09/1969, p. 18; HPLPC, LVI, 11/09/1969, p. 22; HPLPC, LVI, 12/09/1969, p. 18; HPLPC, LVI, 13/09/1969, p. 20; HPLPC, LVI, 25/09/1969, p. 22; HPLPC, LVI, 01/10/1969, p. 14; HPLPC, LVI, 28/02/1970, p. 17; HPLPC, LVI, 14/04/1970, p. 18. 
89 | Por fuera de los sindicatos: experiencias clasistas...

tan pacífica que daba lugar a un momento de distención representado por el ritual argentino de la parrillada. ${ }^{19}$

Unos años más tarde, se inició otro conflicto con la empresa Del Carlo S.A. Allí, a principios de 1972, la firma informó sobre la suspensión de actividades debido a una disminución obligada de la producción, alegando que Renault había achicado a un tercio sus compras cuando Del Carlo le informó del aumento de algunos precios. Los obreros ocuparon por casi 24 horas la planta, manteniendo encerrados a los directivos y al personal administrativo. Finalmente, desalojaron pacíficamente la fábrica cuando supieron de la existencia de una orden judicial de desalojo y vieron el despliegue de efectivos policiales en los alrededores. El mediador entre los obreros y la policía fue nuevamente Alejo Simó, quien se quejó de la injusticia de la orden de desalojo, ya que "en lugar de castigar a los empresarios que dejaban sin trabajo a los obreros, se los amenazaba a ellos". ${ }^{20}$ El conflicto continuó en los días siguientes, cuando los trabajadores fueron informados que, además de ser despedidos, no podrían cobrar sus indemnizaciones. Algunos de ellos levantaron barricadas en las adyacencias de la planta e ingresaron a una fábrica subsidiaria ubicada al lado, que era propiedad de Julio Rosales, socio gerente de Del Carlo. Allí, se dañaron las máquinas, se rompieron vidrios y muebles y se apropiaron de varias herramientas. Luego, se dirigieron a la casa de Rosales, ubicada a dos cuadras de allí y la incendiaron. Por estos hechos fueron detenidos por un breve tiempo Alejo Simó y Juan Carlos Romero, Secretario General y Gremial de la UOM, respectivamente. ${ }^{21}$

Con sus principales dirigentes sindicales presos y procesados, los trabajadores de Del Carlo continuaron activos. Cuando les llegaron los telegramas de despido por "justa causa" (por la ocupación), se reunieron frente a la fábrica para hacer una asamblea. La Policía los dispersó y detuvo a varios cuando comenzaron a armar barricadas. ${ }^{22}$ Por la intensidad del conflicto, en este caso, sí se declaró un paro en todo el sector, que tuvo adhesiones de otros gremios y de la CGT regional. En esa oportunidad, nuevamente hubo refriegas en los alrededores de la fábrica, cuando los obreros intentaron infructuosamente levantar barricadas. La Policía detuvo a 25 personas, incluyendo de nuevo a Alejo Simó, que fue liberado al otro día. No obstante, el conflicto no tuvo retorno y Del Carlo no reabrió sus puertas. ${ }^{23}$

\footnotetext{
${ }^{19}$ Italbó estaba ubicada en Camino a Los Molinos Km 4 y 112 y en ella trabajaban poco más de 50 personas en la producción de llantas para automóviles. HPLPC, LVI, 29/11/1969, p. 19.

${ }^{20}$ La fábrica Del Carlo estaba ubicada en camino a Alta Gracia, en Barrio Las Flores, y se dedicaba a la fabricación de asientos elásticos para autos Renault. Allí, trabajaban poco menos de 280 obreros. BM (Biblioteca Mayor, UNC), Córdoba, 13/01/1972, pp. 1, 4.

${ }^{21}$ Romero solo estuvo preso un día, Simó lo estuvo dos días. En ese tiempo, circuló la noticia de que serían imputados por incendio, daño calificado y usurpación, pero luego no hubo más noticias de procesos judiciales por el hecho. BM, Córdoba, 14/01/1972, p. 1; BM, Córdoba, 16/01/1972, pp. 1, 2; BM, Córdoba, 18/01/1972, p. 1.

${ }^{22}$ BM, Córdoba, 17/01/1972, p. 8.

${ }_{23}$ BM, Córdoba, 21/01/1972 p. 3; BM, Córdoba, 25/01/1972, p. 4; BM, Córdoba, 29/01/1972, p. 4; BM, Córdoba, 01/02/1972 p. 4; BM, Córdoba, 04/02/1972, p. 1.
} 
A pesar de la mediación del sindicato en cada conflicto particular, la crisis que afectaba al sector era profunda y ya había provocado el cierre de varios establecimientos, dejando a cientos metalúrgicos sin trabajo. ${ }^{24}$ En el contexto de crisis del sector, la estrategia del sindicato fue ponerse a la cabeza de los movimientos espontáneos de las bases, liderando las negociaciones, pero evitando confrontaciones de clases. Por la estructura del sindicato, en general, de fábricas medianas y pequeñas, la táctica de la dirección sindical fue mantener la fragmentación de los conflictos en el ámbito de cada establecimiento, sin generar redes de solidaridad que permitiesen expandir los descontentos de las bases ante la crisis de todo el sector. Estos diques de contención, y la efectividad de la dirección en hallar rápidas soluciones a los problemas que aquejaban a los trabajadores metalúrgicos, fueron eficaces en la administración de los descontentos obreros. Sumada a la represión empresaria por el contexto de crisis de sector, el régimen estatutario metalúrgico, acompañado del ejercicio de presiones y amenazas, impidió expresiones institucionalizadas del clasismo entre los metalúrgicos, que no pudo sobrepasar la organización de agrupaciones sindicales.

\section{Las dificultades para el activismo en la construcción}

En la Unión Obrera de la Construcción (UOCRA), filial Córdoba, el modelo de organización fue similar al de la UOM. En primer lugar, porque los lugares de trabajo no reunían a grandes cantidades de trabajadores e, incluso, sus formaciones tenían la temporalidad marcada por el principio y el fin de la obra. Además, porque la dirección del sindicato también estaba alineada con el sindicalismo "ortodoxo" verticalista. Aun así, también se formaron agrupaciones de bases que vieron imposibilitada su expresión institucional, como el Movimiento Unión y Lucha de Obreros de la Construcción, al que la dirección del gremio negaba toda representatividad; o el Movimiento de Recuperación de la Unión Obrera de la Construcción, liderado por Jorge Canelles, crítico del sindicalismo participacionista y de Rogelio Coria, secretario general de la UOCRA nacional. Canelles estaba vinculado al Partido Comunista (PC) y se agrupaba junto a Tosco en el núcleo "independiente". ${ }^{25}$

\footnotetext{
${ }^{24}$ En el caso de Aerometal Petrolini, como la empresa se declaró en quiebra e impidió el arbitrio de soluciones de fondo, el Ministerio de Gobierno dictó su intervención. Pero luego de unos meses la empresa se hallaba paralizada y virtualmente abandonada por sus directivos, así que el gobierno dio por terminada la intervención. Por el mismo tiempo, se ocuparon otras fábricas por problemas similares: la fábrica de carrocerías para colectivos La Unión SRL, ubicada en Av. Colón 1760; la fábrica Ferrari Saccani y Nodulfer S.A., que estaba en Ruta 9, km. 693. En los primeros meses de 1971 hubo paros en otras plantas por retraso en los haberes: en la planta metalúrgica Agrovial Minera, en el Centro Industrial de "Capeto y Rodríguez", ubicada en Bv. Los Granaderos 2055 y en Conarg. También hubo más suspensiones y despidos en la empresa Del Carlo, Domingo Vespasiani y Profile. HPLPC, LVI, 17/06/1970, p. 15; HPLPC, LVI, 14/09/1969, p. 30; HPLPC, LVI, 04/12/1969, p. 20; HPLPC, LVI, 17/12/1969, p. 20; HPLPC, LVI, 03/02/1970, p. 13; BM, Córdoba, 25/01/1971, p. 4; BM, Córdoba, 28/01/1971, p. 4; BM, Córdoba, 19/04/1971, p. 5; BM, Córdoba, 09/06/1971, p. 19; BM, Córdoba, 27/06/1971, pp. 17, 25.

${ }^{25}$ HPLPC, LVI, 11/06/1969, p. 20; HPLPC, LVI, 28/10/1969, p. 18; Córdoba, 10/04/1971, p. 5; Entrevista a M. Anguita, trabajador de la construcción, realizada en Córdoba el 30/09/2011 por Laura Ortiz.
} 
91 | Por fuera de los sindicatos: experiencias clasistas...

El secretario general de este gremio en Córdoba era Rito María Caro, uno de los referentes del sindicalismo peronista "ortodoxo", parte del círculo de confianza de Perón, que había sido vocal de la CD desde 1963 y secretario general desde 1970. Al igual que en la UOM, en la Construcción solo la Lista Marrón dirigida por Caro, cumplía con los requisitos legales y estatutarios para presentarse a las elecciones. ${ }^{26}$ La participación de las bases obreras era muy reducida en este sector: no solo las elecciones tenían un nivel muy bajo de participación -con un ausentismo de alrededor del 40\%-, sino que además era muy bajo el número de afiliados: de unos 10.000 trabajadores del sector, el padrón de afiliados contaba con apenas 1.471.27

La situación de desprestigio de la dirigencia de este sindicato tuvo relación con la no resolución de varios problemas laborales. El principal era la subcontratación, esto es, la práctica patronal de poner a los obreros bajo responsabilidad de una persona sin solvencia económica para evitar pagar los salarios acordados en el convenio y afrontar las cargas sociales, el pago de los días feriados y aguinaldos, la cobertura de enfermedades y accidentes, etc. Tampoco se reformó el fondo de desempleo, que era un sistema que permitía al empleador evitar pagar indemnizaciones. Este fondo funcionaba a través de una libreta que cumplía la función de indemnización, en la que la empresa inscribía todos los años de aportes. Según el sistema, si el trabajador renunciaba al finalizar el primer año de trabajo, le correspondía un 70\% de su indemnización, si lo hacía al segundo año era el $50 \%$ y así continuaba en sentido descendente. De manera que al obrero le convenía renunciar al terminar su primer año de trabajo, lo que acentuaba aún más la condición de temporalidad del trabajo en la construcción. Incluso más, era común tener un acuerdo preestablecido con la empresa para que, luego de renunciar, se continuase trabajando en el mismo lugar. De esta manera, el empleador se ahorraba cargas por antigüedad. Debido a esta situación, y a la pasividad del sindicato frente a estos problemas, era común que los trabajadores no recurriesen al amparo del gremio cuando tenían algún atraso en el pago de sus jornales, lo cual era muy recurrente. ${ }^{28}$ Pero esta pasividad del sindicato en la defensa de los derechos laborales, se contrarrestaba con un ejercicio de la violencia contra los posibles opositores sindicales: a los activistas opositores se les dificultaba la afiliación, la presentación de listas para elecciones e, incluso, corrían riesgos de agresiones físicas.

"Vos en el Sindicato de la Construcción, sos activista, no te podías afiliar. Era imposible afiliarte. Desde amenazas de muerte, de correrte a... a balazos, de todo. No podíamos afi-

\footnotetext{
${ }^{26}$ Construyamos, Órgano de difusión de la UOCRA, seccional Córdoba, Año 1, № 1, septiembre de 1971, pp. 1,5 .

${ }^{27}$ En las elecciones de 1971 en que fue reelegida la Lista Marrón, votaron 889 sobre los 1471 que figuraban en el padrón. La Lista Marrón obtuvo para la CD central (con Rogelio Coria a la cabeza) 856 votos y en blanco 33; para Comisión Ejecutiva seccional Córdoba 887 y en blanco 2 y para el Congreso de Delegados de la CGT 856 y en blanco 33. BM, Córdoba, 06/10/1971, p. 7.

${ }^{28}$ HPLPC, LVI, 17/02/1970 p. 11; BM, Córdoba, 12/06/1971, p. 13; BM, Córdoba, 19/09/1971, p. 4; Construyamos, Año 1, № 1, septiembre de 1971, p. 3, Entrevista a M. Anguita, cit.
} 
liarnos. Todos los dirigentes de ese, o que dirigimos ese proceso, ninguno podía, pudo presentarse en la lista de oposición". ${ }^{29}$

Por la actitud de la dirigencia, el sindicato no era visto como un espacio de participación de los trabajadores, pero en los casos en que hubo interés en participar, la estructura estatutaria del sindicato imposibilitaba la acción clasista que, como en el caso de la UOM, no pudo exceder la organización en agrupaciones sindicales.

\section{El activismo de obreras clasistas en fábricas de calzado}

La producción de calzado correspondía a un sector vegetativo dentro de la distribución porcentual de la industria cordobesa, cuya época de mayor dinamismo en Argentina por su capacidad de crecimiento y tecnificación- se desarrolló en la década de 1920 y 1930 (Kabat, 2005, p. 34). Para los años que examinamos, una de las principales características en la industria del calzado en Córdoba era que la mayoría de su mano de obra era femenina. Si en toda la industria cordobesa el $89 \%$ de la población trabajadora estaba constituida por varones mientras el 11\% restante eran mujeres; en el sector de fabricación de calzado de cuero esa proporción se invertía: el 53\% eran mujeres y el 47\% varones. ${ }^{30}$ La otra característica de este sector, probablemente relacionada con lo anterior, era el altísimo nivel de explotación y de arbitrariedad patronal, como también lo era la pasividad sindical ante estas situaciones. Era común la obligatoriedad de firmar los recibos de sueldo en blanco, los despidos sin causa o la falta de seguridad en las máquinas. Ante estas situaciones, el sindicato debía intervenir, solicitando inspecciones de organismos estatales en las plantas, o bien, reclamando ante la patronal el cumplimiento de la legislación laboral. ${ }^{31}$ Pero, como ello no sucedía, los trabajadores podían recurrir al apoyo de otros sindicatos, o de la regional de la CGT; o bien, autoorganizarse.

En 1970 hallamos los primeros ejercicios de resistencia y autoorganización de las bases de las fábricas del calzado. En la fábrica Italo Brenna, ubicada en Barrio Colón, la patronal quiso obligar a sus trabajadores a cambiar el horario laboral, fraccionando la jornada que era continuada. Las bases resistieron al cambio de horario y, por ello, la empresa decidió despedir a 39 obreras. Un grupo importante de sus 101 trabajadoras acudieron a la CGT y denunciaron, además, que el dueño de la fábrica, que era un militar retirado, pagaba un salario de $\$ 800$ en vez de los $\$ 1.300$ que correspondían de acuerdo al convenio. También expusieron que era común que las obligaran a firmar recibos de sueldo en blanco o por sumas diferentes a las que recibían, completándolos después con la suma que convenía para poder evadir impuestos. Allí, los feriados se trabajaban como jornada simple y los sábados no se consideraban trabajo extra. Esos días, no se permitía

\footnotetext{
${ }^{29}$ Entrevista a M. Anguita, cit.

${ }^{30}$ Instituto Nacional de Estadísticas y Censos, Dirección de Informática, Estadística y Censos de Córdoba (1974). Censo Nacional Económico.

${ }^{31}$ BM, Córdoba, 30/06/1971, p. 18.
}

Anuario de la Escuela de Historia Virtual - Año 9 - Nº 14 - 2018: pp. 81-99. ISSN 1853-7049 
93 | Por fuera de los sindicatos: experiencias clasistas...

marcar tarjeta para evitar el registro de esas ilegalidades..$^{32}$ Raúl Olmedo, presidente del Sindicato del Calzado, fue apuntado como cómplice de la situación de injusticia, que continuó durante todo el período. ${ }^{33}$

Estas expresiones de bases obreras buscaron su constitución como oposición sindical a la "camarilla" de Olmedo. Pero los estatutos y las prácticas de la Unión Trabajadores de la Industria del Calzado de la República Argentina les dificultaban la tarea: desde hacía 24 años se presentaba una sola lista, la Azul y Blanca; y nadie lograba disputar el liderazgo a Olmedo. ${ }^{34}$ Por ello, buscaron organizarse por fuera de la estructura sindical, convocando a opositores de diferentes plantas a reuniones al margen de las asambleas del Sindicato. ${ }^{35}$

En julio de 1971 se formó la Agrupación de Obreros del Calzado "11 de junio" que se definía como la "agrupación que interpreta la voluntad de las bases", y declaraba:

"Que hemos salido a la lucha en defensa de la organización sindical que nos agrupa, en manos de seudos dirigentes que han convertido al Gremio del Calzado en una sucursal de los intereses patronales (...) La unión con todos los hombres honestos del gremio es una de nuestras metas". 36

Por aquellos años, la honestidad era sinónimo de movimiento de bases y de clasismo, y por antonomasia, la corrupción se asociaba a la "burocracia”. Este grupo, apoyado por el Sindicato de Empleados Públicos (SEP), la CGT regional y el SiTraC-SiTraM, convocó a una asamblea y propuso realizarla en el Sindicato de Vendedores de Diarios. Cuando la asamblea se constituyó, sin la presencia de ningún miembro de la conducción - aunque sí estuvo el hijo de Raúl Olmedo tratando de impedir el libre ingreso de los trabajadores-; circuló la versión de que los directivos habían "huido junto a Olmedo en búsqueda de la Policía". Por ello, decidieron mudarse al local de la CGT regional. Allí, se destituyó a la Comisión Administrativa por "inconducta sindical y deslealtad" y se designó una Comisión Administrativa Provisoria. ${ }^{37}$

Hasta aquí el proceso de "rebelión de las bases" es bastante similar al caso de FIAT Concord y Materfer en Córdoba, esto es, se inició con un proceso de autoorganización de las bases por fuera y al margen del sindicato, formando una Comisión Provisoria para destituir a la dirección sindical existente. Sin embargo, comparando el caso del Calzado con el proceso vivido en FIAT, los trabajadores de base del calzado hallaron apoyos sustanciales en la CGT regional, que prestaba sus espacios y recursos para su organización. Es que la CGT, que se había conformado en Córdoba en 1971, era diferente a la de 1970, transformando su identificación peronista "ortodoxa" por una dirección en alianza de

\footnotetext{
32 HPLPC, LVI, 18/09/1970, p. 20.

${ }^{33}$ BM, Córdoba, 12/06/1971, p. 13.

${ }^{34}$ HPLPC, LVI, 15/12/1970, p. 13.

${ }^{35}$ BM, Córdoba, 24/06/1971, p. 13.

${ }^{36}$ BM, Córdoba, 04/07/1971, p. 27.

${ }^{37}$ BM, Córdoba, 14/07/1971, p. 13.
} 
peronistas "legalistas" e "independientes". Por otro lado, el del calzado era un sindicato por rama de producción, por lo que dependía de la Comisión Central de la Unión Trabajadores de la Industria del Calzado. Es decir, la autonomía relativa que tenían los sindicatos de FIAT, por ser sindicatos por planta, no se parecía a la que tenían en el calzado. Por ello, para que la Comisión Provisoria del calzado fuese reconocida, debía ser aprobada por la Central. La misma, al igual que la dirección regional, estaba alineada con el peronismo "ortodoxo" y, en vez de reconocer la comisión formada por las bases, envió una Comisión Interventora a la seccional cordobesa. Para ello, se basó en las acusaciones de Olmedo, que los había tildado de "extremistas, guerrilleros, extranjerizantes", de "conocida filiación comunista" y ajenos al gremio. ${ }^{38}$ No obstante, la Comisión Provisoria sí fue reconocida en el Departamento de Trabajo, donde negoció con la patronal de la firma Blanco Hermanos. Allí, logró dejar sin efecto el despido arbitrario de dos obreros y obtuvo el compromiso patronal de respetar la legislación laboral vigente. ${ }^{39}$

La Central del Sindicato del Calzado envió la Comisión Interventora con gente de Capital Federal, Avellaneda y Rosario. Al principio, esta comisión se diferenciaba de la anterior dirección, ya que se jactaba de haber denunciado incumplimientos de las disposiciones laborales en que incurrían numerosas patronales y de haber reorganizado los Cuerpos de Delegados de las fábricas de calzado Lucas Trejo, Triay Hermanos, Dimaja y Blanco Hnos. Al principio, la Agrupación “11 de junio” apoyó la intervención y suspendió la Comisión Provisoria, pero, al poco tiempo, comenzó a criticarla, argumentando que no eran trabajadores del gremio, en especial, sus asesores, Pedro Albisini y Montesana. En su lugar, proponían formar una "comisión asesora" elegida por las bases y movilizaron a los trabajadores para reclamar la mejora de condiciones laborales. ${ }^{40}$

Al mismo tiempo, la Comisión Interventora comenzó a tener diferencias con el Cuerpo de Delegados de la fábrica Lucas Trejo con motivo del conflicto que se desarrolló en ese establecimiento. De todas las fábricas de calzado de Córdoba, Lucas Trejo es una de las más recordadas por sus conflictos, por su activismo, porque establecieron redes horizontales con sindicatos clasistas como los de FIAT y, sobre todo, porque la gran mayoría de sus delegadas eran mujeres. En Lucas Trejo, al igual que en muchas otras del sector, la arbitrariedad patronal era una tradición. Pero, en 1971, las bases comenzaron a organizarse y a reclamar sus derechos. El inicio del conflicto principal sucedió cuando la patronal despidió al subdelegado Luis Ramón Toledo, por lo que se dispuso una huelga de brazos caídos durante ese día. Pero, luego del descanso del mediodía, cuando se presentaron a continuar con la jornada, se encontraron con la fábrica cerrada, un cordón policial al frente y 170 telegramas de despido. ${ }^{41}$ Unos días después, los trabajadores

\footnotetext{
${ }^{38}$ BM, Córdoba, 12/07/1971, p. 15.

${ }^{39}$ BM, Córdoba, 16/07/1971, p. 13.

${ }^{40}$ BM, Córdoba, 22/07/1971, p. 19; BM, Córdoba, 24/07/1971, p. 17; HPLPC, LVI, 15/08/1971, p. 24; HPLPC, LVI, 21/08/1971, p. 11; HPLPC, LVI, 25/08/1971, p.17; Archivo del SiTraC (AS), Subarchivo № 1, Volantes y Boletines del SITRAC, Ficha № 2, Docs. 52, 63.

${ }^{41}$ HPLPC, LVI, 12/08/1971, p. 17.
}

Anuario de la Escuela de Historia Virtual - Año 9 - N 14 - 2018: pp. 81-99. ISSN 1853-7049 
95 I Por fuera de los sindicatos: experiencias clasistas...

de FIAT Concord hicieron abandono de tareas en solidaridad, marchando desde Ferreyra hasta el Barrio San Vicente donde estaba ubicada la fábrica y, desde allí, continuaron juntos con el Movimiento Clasista de Obreros del Calzado y algunos vecinos del barrio. ${ }^{42}$ La solidaridad con la huelga en Lucas Trejo también fue manifestada por la CGT regional. ${ }^{43}$

El conflicto continuó en los días siguientes, cuando la Agrupación "11 de junio" y el Cuerpo de Delegados de Lucas Trejo convocaron a un paro activo con un acto frente al local de la CGT regional, que fue acatado masivamente, a pesar de las presiones y amenazas de las patronales. ${ }^{44}$ Con el impulso del Cuerpo de Delegados del establecimiento Lucas Trejo y del Movimiento Clasista Obreros del Calzado, una asamblea de trabajadores terminó expulsando a Montesana, el dirigente de la Comisión Interventora. ${ }^{45}$ En cada reunión, en cada acción, las trabajadoras de Lucas Trejo tenían el apoyo de los Sindicatos de Fiat, de la CGT regional y también de la Unión Tranviarios Automotor (UTA), que les prestaban sus locales y les daban asesoramiento, lo que era catalogado por la Comisión Interventora como intromisión "extremista” (Duval, 2001, p. 63).

Los enfrentamientos continuaron y, un par de días más tarde, sumaron agresiones físicas cuando un grupo de unas 20 personas "patoteó" a una asamblea de Lucas Trejo que se estaba realizando en el hall de la CGT regional y donde se habían congregado unas 400 obreras del calzado. Los disparos de armas de fuego y bombas de estruendo se combinaron con golpes de puño y puntapiés a algunas trabajadoras que estaban en la escalera del local. El grupo agresor se identificaba con la escarapela argentina, y fueron calificados por los agredidos como "supuestos nacionalistas que se autotitulaban 'peronistas ortodoxos'”, pero que, según los agredidos, eran "bandas fascistas armadas por la policía del régimen y pagadas por las patronales" ${ }^{46}$ Este hecho demuestra al menos dos cosas. Primero, que la organización de las bases del calzado era capaz de reunir a cuatro centenas de trabajadores en una asamblea, cifra más que significativa considerando que debe haber agrupado a trabajadores de distintas fábricas, que, en general, tenían desde menos de 100 hasta no mucho más de 300 obreros. Vale decir que estaban operando redes horizontales por fuera y al margen de los sindicatos, reuniendo al activismo, cuerpos de delegados y comisiones internas. Segundo, que los trabajadores de bases del calzado se enfrentaban a la cúpula de su propio sindicato, alineada al peronismo "ortodoxo"; y que eran apoyados por la CGT regional y otros sindicatos, alineados al peronismo combativo, al sindicalismo "independiente" y clasista.

\footnotetext{
${ }^{42}$ HPLPC, LVI, 18/08/1971, p. 17; AS, Subarchivo № 1, Ficha № 2, Docs. 62, 72, 73, 74; Protocolo Notarial Registro 3, Escribano Público Ricardo Orortegui: Escritura № 489, sección “B”, Córdoba, 13/08/1971, Fs. 161. ${ }^{43}$ HPLPC, LVI, 20/08/1971, p. 17.

${ }^{44}$ HPLPC, LVI, 23/08/1971, p. 11; HPLPC, LVI, 25/08/1971, p.17.

${ }^{45}$ HPLPC, LVI, 26/08/1971, p. 17; HPLPC, LVI, 30/08/1971, p. 16; HPLPC, LVI, 31/08/1971, p. 11.

${ }^{46}$ También la Agrupación "11 de junio" emitió un comunicado en el que responsabilizaba a la Intervención del Sindicato del Calzado por convocar a "matones a sueldo para intimidar a los trabajadores". HPLPC, LVI, 28/08/1971, p. 10.
} 
Para los empresarios del sector, la mala situación de los trabajadores y los despidos se debían a una crisis generalizada de esta rama productiva. Según sus argumentos, estaban siendo perjudicados por la obligatoriedad de comprar materia prima y maquinaria en Buenos Aires, lo que aumentaba los costos de producción. En efecto, la patronal de Lucas Trejo había manifestado que, ante esta situación, debería cerrar definitivamente la planta y, por ello, los delegados, asesorados por el Dr. Curutchet, solicitaron al gobierno la expropiación de la fábrica para reactivar y reabrir la fuente de trabajo. ${ }^{47}$ Ese pedido quedó suspendido por un tiempo, desde septiembre de 1971 hasta agosto de 1975, ciertamente, debido a los vaivenes políticos de la provincia.

\section{El clasismo en fábricas de vidrio}

En las fábricas del vidrio la situación no era muy diferente a las del calzado. No solo porque la mayor parte de las trabajadoras eran mujeres, sino también porque cada liquidación de sueldos podía demorar, o liquidarse sin los premios correspondientes o las asignaciones por casamiento, o sin respetar el escalafón. Cada paro era seguido de despidos, como sucedió en la empresa LESA (Lámparas Especiales SA) que en 1969 despidió a 5 jóvenes trabajadoras por "razones gremiales", ya que habían participado de un paro la semana anterior. ${ }^{48}$ En muchas fábricas no había Cuerpo de Delegados ni Comisiones Internas, no por falta de interés de los trabajadores, sino por la oposición patronal y la connivencia de la dirección sindical. Las condiciones laborales eran malas, faltaba la ventilación y los techos a veces no eran los apropiados para talleres que levantaban altísimas temperaturas, donde tampoco se les proveía a las trabajadoras de agua potable refrigerada. ${ }^{49}$

El Sindicato de Obreros de la Industria del Vidrio y Afines, seccional Córdoba, intentaba administrar los descontentos de las bases para que no se desbordasen. Al igual que otros casos mencionados, ante cada conflicto en una fábrica específica, la dirección sindical intentaba resolverlo dentro de los márgenes de ese establecimiento, y se sentaba a negociar con la patronal por mediación del Departamento Provincial de Trabajo. ${ }^{50}$

\footnotetext{
"El sindicato aparecía eh, eh, comienza en realidad a aparecer el sindicato cuando empiezan a aparecer los volantes [de la oposición]. El sindicato siempre había ido a cobrar la cuota mensual; no de los trabajadores sino de la patronal. El Sindicato del Vidrio era lo más... era de derecha, y lo más esteee reaccionario, lo más burócrata que pueda haber. Las chicas lo odiaban, eran los 'panzones'”. 51
}

\footnotetext{
${ }^{47}$ BM, Córdoba, 08/09/1971, p. 4; BM, Córdoba, 09/09/1971, p. 9; 19/09/1971, p. 3; BM, Córdoba, 23/09/1971, p. 5.

${ }^{48}$ También hubo este tipo de conflictos en CIVE S.A. y en Lumitron S.A. HPLPC, LVI, 29/08/1969, pp. 10-11.

${ }^{49}$ BM, Córdoba, 11/02/1972, p. 4.

${ }^{50}$ HPLPC, LVI, 12/08/1969, p. 18; HPLPC, LVI, 25/09/1969, p. 22; HPLPC, LVI, 02/10/1969, p. 18; HPLPC, LVI, 18/12/1969, p. 19; HPLPC, LVI, 20/05/1970, p. 19.

${ }^{51}$ Entrevista a M. C. Carranza, cit.
} 
97 | Por fuera de los sindicatos: experiencias clasistas...

Jorge Luis Luján, su Secretario General desde hacía muchos años, mantenía el control de la dirección sindical en elecciones en las que se presentaba una única lista, la Azul y Blanca. También controlaba las comisiones internas y, en caso de que alguna quisiera oponerse a su dirección, se enviaba la intervención. Así sucedió en agosto de 1970 con la Comisión Interna de Reclamos (CIR) de la empresa LESA-OSRAM, donde gran parte se identificaba con una agrupación opositora a Luján: la Agrupación "Activistas del Vidrio". Como habían participado, con el apoyo de los operarios, en un paro dispuesto por CGT regional, la CIR fue intervenida por la Dirección Nacional del Sindicato del Vidrio y se sancionó sindicalmente a sus integrantes. ${ }^{52}$

Los "Activistas del Vidrio" se reunieron con otros cuerpos de delegados de bases de fábricas de la zona y formaron el Movimiento Interfabril San Carlos. Allí, participaban militantes de la Agrupación Vanguardia Metalúrgica, del Cuerpo de Delegados de Transax que militaban en Política Obrera, militantes del PC de Corcemar y de EPEC, activistas de la fábrica Morchio y Benítez y de otras fábricas. ${ }^{53}$ Comenzaron a establecerse redes horizontales entre los activistas de izquierda de las distintas fábricas del vidrio en vistas a organizarse. Se reunieron activistas de la fábrica de parabrisas CIVE, de una fábrica de damajuanas de Deán Funes, y de las dos fábricas de lámparas de la ciudad de Córdoba, LESA-OSRAM y Lumitron. Incluso, llegaron a formar una lista, la Lista Rosa, pero no pudieron presentarse a elecciones, aunque creían tener posibilidades de ganar. ${ }^{54}$ Los conflictos entre la dirección y los activistas de la oposición, reunidos en una "Comisión de Lucha", continuaron. A principios de 1972 el sindicato impuso una retención masiva de la cuota sindical sobre el 15\% del aumento salarial ganado. Por cierto, esta medida sin consulta previa fue resistida por los trabajadores que pidieron la renuncia de la $\mathrm{CD}$ en una asamblea que terminó en forcejeos y la dispersión a balazos de las bases por parte de la conducción. ${ }^{55}$ Una de las delegadas recuerda ese momento de mucha violencia, tanto de parte de la dirección sindical como del activismo:

"Y después al tiempo fui delegada por la elección de la gente. Y comooo pedíamos cosas, o sea era obvio que había que pedir papel higiénico, que había que pedir uniformes, que había que pedir más higiene y bueno determinadas cosas digamos que hacen al, a, a looo, a lo laboral. Ehhh, al gremio por supuesto que, y bueno siguen manejando, o sea, los gremios siguen manejando todo. Ehhh... nos sacaron de, del gremio y no, o sea nosotros por ejemplo creo que nos descontaban la cuota sindical pero no pertenecíamos más al gremio (...) Ymmm... asambleas, ehhh, de de estar con revolvers (sic) calzaditos o mostrando el revólver sobre la mesa como para amedrentar yyy, y que nosotro (sic) aceptáramos lo que ellos decían. Y por supuesto que aún sin experiencia es una cosa matemática que vos decís dos más dos es cuatro, o sea, yo tengo que exigir esto, como por ejemplo el papel higiénico. Yyy por supuesto no, nos sacaron, pero previo eh eran, eran batallas campales porque yo me acuerdo cuando el gremio estaba acá en la calle Santa Rosa, había chicas, o sea una de las delegadas que es, debe ser un poco más joven que yo, poca edad digamos, pero una

\footnotetext{
${ }^{52}$ HPLPC, LVI, 23/08/1970, p. 29; HPLPC, LVI, 01/09/1970, p. 15.

${ }^{53}$ Entrevista a M. C. Carranza, cit.

${ }^{54}$ Ibíd.

${ }_{55}$ BM, Córdoba, 30/01/1972, p. 4; BM, Córdoba, 01/02/1972, p. 3; BM, Córdoba, 02/02/1972, p. 1.
} 
chica más joven; eh, escuchame, agarraban piedras de la calle y les tiraban. Que, que uno en otra forma era como que trataba de que hubiera un orden para poder dialogar. Pero por supuesto que no se podía dialogar porque el objetivo de ellos era, era otro. Yyy, y bueno por supuesto que molestábamos o sea que nos tu, nos sacaron. Yo digo tener por ejemplo la, la, lugares que te corresponden, que son nuestros, y jno podíamos porque el, el gremio nos había sacado!"56

Por más piedras que tirasen y batallas campales que intentasen las jóvenes delegadas que querían ser reconocidas como interlocutoras de las bases, el sindicato contaba con las herramientas necesarias para mantener el control de los descontentos de las bases: la expulsión.

\section{Conclusiones}

El presente artículo describe las experiencias clasistas durante el período 1969-1971, en algunas fábricas metalúrgicas, obras de construcción, fábricas de calzado y de vidrio. En todas ellas el clasismo tuvo diferentes formas y contenidos, aunque, sin embargo, también presenta elementos que permiten agruparlas, no solo por el período en que sucedieron, sino también por las condiciones históricas que las generaron y por sus modalidades de organización. En este recorrido hemos analizado casos en los que la emergencia de estos movimientos clasistas tuvo más relación con una situación de descontento obrero, que no tuvo canalización a través de la estructura sindical existente, y que, por lo tanto, buscó caminos por fuera y al margen de ella. Para ello, fue sustancial la constitución de redes horizontales que permitían ampliar los apoyos en casos de conflictos, tanto dentro de un mismo sector como entre distintos sindicatos. En todos ellos encontramos activistas que se autodenominaban clasistas, o adscribían a Movimientos de Recuperación Sindical, que era otra forma de identificarse. En algunos casos estuvieron vinculados a algún tipo de organización política de izquierda, aunque esto no siempre se tradujo en un discurso revolucionario.

Durante el período analizado, la represión empresaria se manifestaba constantemente con despidos, traslados selectivos, lock-outs y muchas otras formas. Por ello, los reclamos obreros debían considerar esa violencia como una posibilidad. Pero, además, en esos años el gobierno de facto aplicaba altas dosis represivas, de manera que las acciones de los clasistas debían contemplar la posibilidad de un desalojo a manos del Ejército y, por ello, las tomas de fábricas con rehenes y rodeadas con tanques de combustible fueron la medida de fuerza que más los caracterizó. Esas posturas fueron tildadas de "ultraizquierdistas" y, por ello, sus sindicatos fueron intervenidos o no reconocidos, los activistas perseguidos y encarcelados, y el discurso dominante definía a estos grupos como "extremistas", "extranjerizantes" y "subversivos".

\footnotetext{
${ }_{56}$ Entrevista a Norma, delegada de la fábrica Cindalux (Vidrio), realizada en Córdoba el 24/08/2011 por
} Laura Ortiz. 
99 | Por fuera de los sindicatos: experiencias clasistas...

En los casos analizados, la autoorganización de las bases no logró institucionalizar una alternativa a la dirección sindical "ortodoxa", ya sea a través de la formación de listas sindicales opositoras o de comisiones provisorias que reemplazasen al sindicato. El acceso de la dirigencia tradicional a diferentes formas de violencia fue eficaz para controlar esos movimientos de bases y evitar su acceso al poder sindical: un manejo discrecional del sistema electoral que limitaba las posibilidades de presentaciones de listas opositoras, la expulsión de activistas clasistas, la selección de quiénes podían afiliarse y quiénes no, de acuerdo a su posicionamiento sindical y político; además, se recurrió a las amenazas y al ejercicio de la violencia física.

\section{Referencias Bibliográficas}

Altamirano, C. (1994). Memoria del '69. Estudios, 4, 9-13.

Brennan, J. y Gordillo, M. (1994). Protesta obrera, rebelión popular e insurrección urbana en la Argentina: el Cordobazo. Estudios (4), 51-74.

Duval, N. (2001). Los sindicatos clasistas: SiTraC (1970-1971). Córdoba: Fundación Pedro Milesi.

Flores, G. (2004). SITRAC-SITRAM. La lucha del clasismo contra la burocracia sindical. Córdoba: Editorial Espartaco.

Franco, M. (2012). Un enemigo para la Nación. Orden interno, violencia y "subversión", 1973-1976. Buenos Aires: Fondo de Cultura Económica.

Garzón Maceda, L. (1994). Cordobazo: algunos de sus mitos y leyendas. Estudios, 4, 25-34.

Gordillo, M. (1996). Córdoba en los '60: la experiencia del sindicalismo combativo. Córdoba: Dirección general de publicaciones de la UNC.

Gordillo, M. (Ed.) (2001). Actores, prácticas, discursos en la Córdoba combativa. Una aproximación a la cultura política de los '70. Córdoba: Ferreyra Editor.

James, D. (2005). Resistencia e integración. El peronismo y la clase trabajadora argentina, 1946-1976. Buenos Aires: Siglo XXI Editores.

Kabat, M. (2005). Del taller a la fábrica. Proceso de trabajo, industria y clase obrera en la rama del calzado (Buenos Aires, 1870-1940). Buenos Aires: Ediciones ryr.

Mignon, C. (2014). Córdoba obrera. El sindicato en la fábrica, 1968-1973. Buenos Aires: Imago Mundi.

Ollier, M. M. (1986). El fenómeno insurreccional y la cultura política (1969-1973). Buenos Aires: CEAL.

Ortiz, M. L. (2010). Apuntes para una definición del clasismo. Córdoba, 1969-1976. Conflicto Social, 3 (3), 5983. Recuperado de: http://webiigg.sociales.uba.ar/conflictosocial/revista/03/sumario3.htm (consultado el 10/07/2018).

Tortti, M. C. (1998). Protesta social y "nueva izquierda" en la Argentina del “Gran Acuerdo Nacional”. Taller. Revista de Sociedad, Cultura y Política, 3 (6), 11-39.

Werner, R. y Aguirre, F. (2009). Insurgencia obrera en la Argentina 1969-1976. Clasismo, coordinadoras interfabriles y estrategias de la izquierda. Buenos Aires: Ediciones IPS.

\section{Para citar este artículo:}

Ortiz, María Laura (2018). Por fuera de los sindicatos: experiencias clasistas en fábricas pequeñas y medianas de Córdoba, 1969-1971. Anuario de la Escuela de Historia Virtual, 14, 81-99. 